\title{
BMJ Open Validity and feasibility of a self- administered home vision examination in Yueqing, China: a cross-sectional study
}

\author{
Zhengyan Ge, ${ }^{1}$ Linshan Li, ${ }^{1}$ Lynne Lohfeld, ${ }^{1,2}$ Chunjie Lu, ${ }^{1}$ Nathan Congdon, ${ }^{2,3}$ \\ Sigeng Lin, ${ }^{1}$ Yuxuan Deng, ${ }^{1}$ Yuan Lan, ${ }^{1}$ Shaodan Zhang, ${ }^{1}$ Laurence Hou, ${ }^{4}$ \\ Weihe Zhou, ${ }^{1}$ Lele Cui, ${ }^{1}$ Jia Qu (D) , ${ }^{1}$ Yuanbo Liang ${ }^{1}$
}

To cite: Ge Z, Li L, Lohfeld L, et al. Validity and feasibility of a self-administered home vision examination in Yueqing, China: a cross-sectional study. BMJ Open 2020;10:e030956. doi:10.1136/ bmjopen-2019-030956

- Prepublication history for this paper is available online. To view these files, please visit the journal online (http://dx.doi. org/10.1136/bmjopen-2019030956).

Received 10 April 2019 Revised 13 March 2020 Accepted 23 March 2020

Check for updates

(c) Author(s) (or their employer(s)) 2020. Re-use permitted under CC BY-NC. No commercial re-use. See rights and permissions. Published by BMJ.

${ }^{1}$ The Affiliated Eye Hospital, School of Ophthalmology and Optometry, Wenzhou Medical University, Wenzhou, China ${ }^{2}$ Centre for Public Health, Queen's University Belfast, Belfast, UK

${ }^{3}$ State Key Laboratory of Ophthalmology, Zhongshan Ophthalmic Center, Sun Yat-sen University, Guangzhou, China

${ }^{4} J o h n s$ Hopkins University

School of Medicine, Baltimore, Maryland, USA

Correspondence to

Dr Jia Qu; qujia@eye.ac.cn

\section{ABSTRACT}

Objective To investigate the validity and feasibility of a self-administered home vision examination programme in China.

Design Cross-sectional study.

Setting Yueqing, China.

Participants A two-stage convenience sampling procedure was used to randomly select 600 households from 30 communities participating in the Yueqing Eye Study (YES). The aim of YES is to encourage home-based vision screening, reporting of visual acuity (VA) annually through social media and encouraging people to attend follow-up clinic appointments as a way to improve eye care access for adults with VA $\leq+0.5$ log of the minimum angle of resolution (logMAR).

Interventions Household screeners (one per household) who tested other family members' VA completed a questionnaire on family structure, demographic information and knowledge about screening procedures. Other family members then underwent confirmatory VA testing by researchers.

Outcome measures The completion rate of home-based VA screening, its sensitivity and specificity were used to evaluate validity. Factors that determined whether families participated in the self-VA screening were used to evaluate feasibility.

Results $345(66 \%)$ of the $523(87.2 \%)$ households with valid data form their home-based vision examinations also were retested by researchers. There was no statistically significant difference in scores on the family-administerd or researcher-administerd VA test $(\mathrm{VA} \leq+0.5 \log \mathrm{MAR}$, $p=0.607 ; V A>+0.5 \log M A R, p=0.612)$. The sensitivity and specificity of home-based vision screening were $80.5 \%$ (95\% Cl $70.2 \%$ to $86.9 \%)$ and $95.1 \%(95 \%$ Cl $92.6 \%$ to $96.8 \%)$, respectively. $14.7 \%(77 / 523)$ of tested respondents had VA $\leq+0.5 \log$ MAR. Predictors of performing home screening for VA remaining in regression models included higher economic status ('fair and above' vs 'poor': OR 1.74; $95 \% \mathrm{Cl} 1.08$ to $2.76 ; \mathrm{p}=0.022$ ), age ( $<45$ years vs $\geq 45$ years: $0 R \quad 0.46$; $95 \% \mathrm{Cl} 0.25$ to 0.85 ; $\mathrm{p}=0.014)$ and living in a nuclear $(\mathrm{OR} 5.17 ; 95 \% \mathrm{Cl} 2.86$ to 9.36; $p<0.001)$ or extended family (OR $8.37 ; 95 \% \mathrm{Cl} 4.93$ to $14.20 ; p<0.001)$.

Conclusion Self-administered home vision screening is reliable and highly accepted by Chinese adults.

\section{Strengths and limitations of this study}

- First study to measure the validity and feasibility of a self-administered home vision examination for adults in China.

- The cross-sectional design does not allow the drawing of causal relationships.

It will reflect an underestimated vision testing result if lay people do not put the eye chart in the right circumstance.

The study lacks a formal cost-effectiveness analysis.

\section{INTRODUCTION}

Vision loss due to eye diseases is a major health problem, greatly affecting quality of life. ${ }^{12}$ Globally, it is estimated that 217 million persons have moderate to severe vision impairment (VI), and 36 million people are blind. ${ }^{3}$ Approximately $80 \%$ of moderate to severe VI and blindness among adults can be successfully avoided or treated if diagnosed in time. ${ }^{4}$ Unfortunately, population studies, including Rapid Assessments of Avoidable Blindness in many underserved regions of the world, show that a large proportion of VI remains undiagnosed and untreated. ${ }^{5}{ }^{6}$ Untreated VI imposes direct and indirect burdens on affected individuals, families and society as a whole. Indirect costs include welfare losses incurred when raising taxes to fund public healthcare, and reduced economic output (productivity) of individuals with vision loss directly due to reduced workforce participation, and the value of time spent by relatives and friends providing informal care. ${ }^{7}$

Screening can identify people with vision loss at an early phase of eye disease, and can lead to timely treatments to improve vision. A large proportion of referrals for patients with eye disease come from community optometric services in many developed countries such as Britain, Australia and America. ${ }^{8-10}$ However, this screening model requiring 
economic investment and a cadre of well-trained optometrists is not necessarily applicable in low/middle-income countries like China because of the undeveloped public health system.

Home-based disease screening models are highly suitable for use in low-resource or isolated communities, because relatively few healthcare resources are needed and therefore costs are reduced. Such screening programmes are now increasingly used to identify and refer at-risk persons for diagnosis and treatment of diseases such as diabetes, hypertension and colorectal cancer. ${ }^{11}{ }^{12}$ The aim of the current study is to investigate the validity and feasibility of a self-administered home vision examination in Wenzhou, China.

\section{MATERIALS AND METHODS}

Oral informed consent was obtained from adults enrolled in the original Yueqing Eye Study (YES), and was sought again from all participants prior to collecting the follow-up screening and survey data in this sub-study.

\section{Study population and sample}

This substudy was based on the YES project, a trial of a home-based visual acuity (VA) screening model in Wenzhou, China. The Yueqing municipal government selected 5 of 16 districts comprising a total of 250 communities (each containing about 500 households) to participate in the YES project, based on their similar high economic level. The YES project aimed to train local community-dwellers to serve as family screeners for their household members, requesting that each resident's vision be examined annually and reported to the YES project's information centre using WeChat, a popular Chinese social media and communication application. All participants with presenting visual acuity (PVA) in either eye $\leq+0.5 \log$ of the minimum angle of resolution ( $\log$ MAR) were eligible for free follow-up examinations at a nearby eye clinic. In consideration of the high prevalence rate of moderate visual impairment in China and the limited funding of establishing free local eye clinics, we decided to use the moderate visual impairment (VA $\leq+0.5$ $\log$ MAR) as the referral standard in the initial implementation stage of the YES project. In order to simplify the operation of self-VA examination and improve adherence of this model, we only screen the distance visual impairment as the programme gears up. We will focus on the impact of near vision on the living quality for people after improving their eye health awareness and changing their doctor-seeking behaviour.

For the present substudy, a two-stage sampling plan was used to select households in the five communities. The WeChat reporting rate for a community was defined as the number of households reporting their VA results divided by the total number of eligible households. In the first stage, a convenience sample of 30 communities with a WeChat reporting rate $>30 \%$ between 1 August and 31 October 2017, among a total of 55, was identified by the project leader. In the second stage, a simple random sampling plan was used to identify 20 households from the census list of participating households in each of the 30 communities, for a total of 600 households were invited to participate in the study. Family screeners who had been trained in VA testing by community screeners and were asked to complete a questionnaire (see below) at the time of a home visit by study personnel, and their family members were invited to undergo confirmatory VA testing by researchers. If no one was home when the research team visited a designated household, three more visits were made at different times on the same day. If no contact could be made, five telephone calls were made over the next 3 days to invite the designated household member to join the study and to collect baseline data.

Persons not contactable in this fashion were excluded from the sub-study, as were those previously diagnosed with a terminal illness or a mental disorder, or living alone, because they lacked a family member on whom to carry out VA screening. To be eligible to take part in the YES project, potential participants were required to have been living in one of the 30 designated study communities for at least 6 months, aged 18 years or older, able to communicate effectively in Mandarin Chinese or the local Yueqing dialect, and willing to give informed consent to participate in the study.

\section{Data collection}

In the present sub-study, trained community screeners distributed the standard logMAR Tumbling-E VA charts (GB 11533-2011, Xingkang Medical Technology, Wenzhou, China) to all participating households between 1 August and 31 October 2017. This chart has 14 rows with a fixed angle increasing rate of $\sqrt[10]{10}$ and progression ranging from $+1.0 \log$ MAR to $-0.3 \log$ MAR. Alough the LogMAR chart has some limitations, such as no uniform use of brightness and illuminance, and eye clinics in China use a truncated LogMAR chart (two rows are missing, 0.7 and 0.9, decimal record method), making it difficult to compare with the international standard VA chart (the Early treatment diabetic retinopathy study (ETDRS) VA chart). ${ }^{13}$ We do not impose strict requirements on the VA screening in this project because it is the first step to screen for eye diseases. Since 2011, it has been widely used to conduct preliminary vision screenings and physical examinations for those aged 3 years and above. There are two different versions of using distance for this chart, that is, used at a distance of $5 \mathrm{~m}$ or $2.5 \mathrm{~m}$. In consideration of the limited space in many Chinese homes, we decreased chart distance from $5 \mathrm{~m}$ to $2.5 \mathrm{~m}$ and minimised the charts' optotype size to guarantee tesing accuracy. The charts included written and pictorial instructions to secure the chart to a smooth wall $1 \mathrm{~m}$ from the floor under bright natural light, and to mark a spot $2.5 \mathrm{~m}$ directly in front of the chart for the person being tested to stand.

Community screeners taught one family member who was willing to be a family screener in each household how 
to perform home vision testing using the provided charts (including the cut-off for referral, see below), and relayed information about three nearby free eye clinics. These clinics are financed by the Yueqing Municipal Government with additional support from the Eye Hospital of Wenzhou Medical University to ensure adequate medical staff and resources are available to meet demand.

With the left eye occluded by the participant's hand, testing began with the right eye using the top line of the chart $(+1.0 \log \mathrm{MAR})$, and then proceeded to line $2(+0.9$ logMAR), line 4 (+0.7 logMAR), line 6 (+0.5 logMAR), line $11(0 \log \mathrm{MAR})$ and line $14(-0.3 \log \mathrm{MAR})$, respectively, if the participant could read half or more of the optotypes on a given line. The vision recorded in the eye was the lowest on which the participant could read half or more optotypes. The test was then repeated for the left eye. Results were reported by the family screener to the YES information centre on WeChat. Participating screeners were asked to test and report results for each adult in the household annually. Test subjects with PVA $\leq+0.5 \log$ MAR in either eye received a referral through WeChat to one of three local eye clinics for a free ocular examination.

In the present sub-study, six project staff trained in vision testing by the Eye Hospital of Wenzhou Medical University performed confirmatory vision testing on residents of the designated household and provided a self-administered questionnaire to the family screeners on family structure, personal demographic informationand knowledge about the YES project referral protocol between 1 November and 31 December 2017, approximately 3 months after the initial household visit. A household was considered to have successfully completed home-based screening if the family screener had performed and reported VA testing on at least one family member.

For the purpose of this sub-study, a family was defined as two or more people living at their current address for at least 6 months prior to being enrolled in the YES programme. Following Turagabeci et al, ${ }^{14}$ we defined family types as: 'couple' (two persons, married or not), 'nuclear family' (couple plus unmarried child/children) and 'extended family' (three or more generations of grandparent(s), parent(s) and child(ren)).

\section{Statistical analysis}

Epidata (V.3.1, The Epidata Association, Odense, Denmark) was used to create the database. Double data entry was performed by graduate students at the School of Ophthalmology and Optometry, Wenzhou Medical University.VA was reported using the mean and with $95 \%$ CIs. Results from home measured VA were compared with those examined by the research team.In using the MannWhitney U test to compare different groups, we found VA distribution in each group to be abnormal. The sensitivity and specificity of the home-assessed model were calculated and the $95 \%$ CI was calculated using the modified Wald method. Continuous variables such as age were presented as means $\pm \mathrm{SD}$, and differences between groups were assessed using analysis of variance. Categorical data were described with numbers and percentages (\%), and differences across family structures and VA results obtained from trained researchers were tested using Pearson's $\chi^{2}$ tests, or with Fisher's exact test if observed frequencies were $<5$ in any cell of the $2 \times 2$ table. Univariate logistic regression was used to analyse the impact of participants' personal demographic information and family structure on whether home vision testing was performed and reported on at least one family member. Multivariate logistic regression was used to analyse the relationship between family structure and demographic variables after adjusting for those variables significantly associated with the outcome in univariate analysis. All analyses were performed using SPSS (V.21; International Business Machines). All tests were two sided and a $\mathrm{p} \leq 0.05$ was considered to be statistically significant.

\section{Patient and public involvement}

Participants and public were not invited to comment on the study design, not consulted to recruit participants and develop outcomes or disseminate the results. Public involvement for the research was obtained primarily informing the district commissioner and various stakeholders. Participants and project staff members were fully involved in this study. Study objectives, benefits and mandatory information was explained to participants. An informed consent was obtained from every participant before filling in the questionnaire. Six project staff members (ophthalmologist or optometrist) trained in standard vision testing engaged in the data collection process.

\section{RESULTS}

Among the 600 eligible family screeners, $87.2 \%$ (523/600, $44.1 \%$ men, mean age of $56.8 \pm 13.5$ years) provided valid data. Non-participation was due to refusal ( $n=33,42.8 \%)$, not being available for the household visit $(\mathrm{n}=15,19.5 \%)$ and living alone $(\mathrm{n}=29,37.7 \%)$. Two-thirds $(345 / 523$, $66.0 \%$ ) of participants had tested at least one family member by the time they were rescreened by the research team.

A total of 523 people from 345 households had their VA results retested. VA results between the layperson's home-based screening and the research team's examination had no statistical difference (VA $\leq+0.5 \log \mathrm{MAR}$, $\mathrm{p}=0.607 ; \mathrm{VA}>+0.5 \log \mathrm{MAR}, \mathrm{p}=0.612)$ (table 1$)$. Of the 77 subjects with an expert examination indicating VA less than $+0.5 \log$ MAR, 62 were detected by a family member conducting a home-based vision screening. Therefore, the sensitivity of the home-based vision screening is $80.5 \%$ (95\% CI $70.2 \%$ to $86.9 \%$ ). Among the 446 participants with an expert examination indicating VA greater than $+0.5 \log$ MAR, 424 passed thehome-based screening tests. Thus, the specificity of the screening package is $95.1 \%$ (95\% CI $92.6 \%$ to $96.8 \%$ ). Details are shown in table 2. Although a total of $77(77 / 523,14.7 \%)$ tested 
Table 1 Comparison of VA between the home-based screening and research team examinations

\section{VA, Log MAR}

\begin{tabular}{|c|c|c|c|}
\hline & $\begin{array}{l}\text { Home measured } \\
\text { Mean }(95 \% \mathrm{Cl})\end{array}$ & $\begin{array}{l}\text { Research team } \\
\text { Mean }(95 \% \mathrm{Cl})\end{array}$ & $P$ value \\
\hline $\begin{array}{l}\mathrm{VA} \leq+0.5 \\
\text { logMAR }\end{array}$ & 0.67 (0.71 to 0.63$)$ & 0.70 (0.75 to 0.65$)$ & 0.607 \\
\hline $\begin{array}{l}V A>+0.5 \\
\text { logMAR }\end{array}$ & 0.12 (0.13 to 0.10$)$ & 0.12 (0.13 to 0.11$)$ & 0.612 \\
\hline
\end{tabular}

logMAR, log of the minimum angle of resolution; VA, visual acuity.

participants with VA results $\leq+0.5 \log$ MAR were recommended to the local eye clinics for follow-up examinations, only $24.7 \%(19 / 77)$ went to the clinic for further examination 6 months later.

Table 3 shows the demographic information of family screeners from 523 household. Nearly two-thirds $(64.6 \%$, $338 / 523)$ of participants reported never having visited an eye clinic. Low educational level $(<$ middle school) and unemployment were more common among couples than for those living in nuclear or extended families. Couples were also significantly more likely to report having an eye disease or chronic disorder. The average age of subjects living as a couple (64.8years, SD 11.8 years) was significantly greater than that for members of nuclear or extended families (53.0years, SD 11.2; and 55.7years, SD 14.0, respectively, $\mathrm{p}<0.001$ for both). Some two-thirds $(67.9 \%, 355 / 523)$ of participants could identify the location of their local free eye clinic, and nearly half $(49.5 \%$, $259 / 523$ ) could recall the cut-off for requiring a more detailed examination ( $\mathrm{PVA} \leq+0.5 \log \mathrm{MAR}$ in either eye).

In multivariate regression models, having screened family members was associated with higher economic status, younger age and having a nuclear or extended family structure(table 4). Subjects self-rating their economic status as 'fair and above' were twice as likely to carry out a vision test on their family members than those with a 'poor' economic situation (OR 1.74; 95\% CI 1.08 to $2.76 ; \mathrm{p}=0.022$ ). Additionally, participants aged $>45$ years were significantly less likely to have screened family members than those aged $\leq 45$ years (OR $0.46 ; 95 \% \mathrm{CI}$ 0.25 to $0.85 ; \mathrm{p}=0.014)$. Significantly, more participants living in nuclear or extended families had completed screening than those living as couples (Nuclear families:

\section{Table 2 Validity of home-based vision examination}

\begin{tabular}{llcc}
\hline & \multicolumn{2}{c}{ Research team } & \\
\cline { 2 - 3 } Home measured & VA $\leq+\mathbf{0 . 5}$ & VA $>+\mathbf{0 . 5}$ & Total \\
\hline VA $\leq+0.5$ & 62 & 22 & 84 \\
VA $>+0.5$ & 15 & 424 & 439 \\
Total & 77 & 446 & 523 \\
\hline
\end{tabular}

Sensitivity, $62 / 77$ or $80.5 \%$ (95\% Cl $70.2 \%$ to $86.9 \%$ ). Specificity, $424 / 446$ or $95.1 \%$ ( $95 \% \mathrm{Cl} 92.6 \%$ to $96.8 \%)$.

VA, visual acuity;
OR 5.17; 95\% CI 2.86 to 9.36 ; $\mathrm{p}<0.001$; extended families: OR $8.37 ; 95 \%$ CI 4.93 to $14.20 ; \mathrm{p}<0.001$ ).

\section{DISCUSSION}

The present study used a home-based vision screening model to establish the habit of checking family members' VA annually among participating households to promote early detection and treatment of visually significant eye diseases in the long term. This model mainly relies on the validity and feasibility of a self-administered home vision examination. Our study shows no consistent evidence to support differences in VA resultsbetween home-based screening and professional examinations. The selfadministered home vision screening model also provides effective first level eye disease screening with a high sensitivity and specificity. A majority of households completed the home-based vision examination, and nearly $15 \%$ of participants obtaining results of PVA $\leq+0.5 \log$ MAR were referred to local eye clinics for follow-up examinations. Residing in nuclear or extended families, which exceed two-thirds of Chinese households, ${ }^{15}$ was significantly associated with a greater likelihood of having carried out home-based vision screening, even after adjustment for other factors. In consideration of these results, the familybased eye disease screening model seems to be suitable for use in China.

Findings in the current study indicate that VA test results obtained by lay persons were comparable to those of trained ophthalmologists using the same at-home method, which indicated that the self-administered home vision examination might be the first step of a satisfactory eye disease screening tool. This result is consistent with previous reports on home-based vision screening programmes for preschool-aged children in China ${ }^{15}$ and amblyopia in South Korea. ${ }^{16}$ In the home-based amblyopia screening system for preschoolers, ${ }^{15}$ the sensitivity of the VA test conducted by parents was $80.0 \%$ and its specificity was $94.1 \%$. In contrast, the current screening model conducted by lay people detected VA in adults, which made the sensitivity of this model $80.5 \%$. At the same time, its specificity was also rather satisfactory (95.1\%).

Not requiring professional knowledge or expertise in screening eye disease, the home-based VA screening model has arelatively high completion rate over a short time span, indicating this model may be appropriate for population vision screening on a larger scale. A key advantage to home-based programmes is improved access to medical care under the home monitoring system. Many home-based approaches to screening, monitoring, and treatment of conditions such as cardiovascular disease, mental disorders and vision problems in children have been evaluated for their effectiveness. ${ }^{15-18}$ However, it was noted that this home-based VA screening model hada low referral rate in participants with PVA $\leq+0.5 \log$ MAR. Previous studies demonstreate that eye care referral barriers includetransportation, family financial status, lower basic eye care knowledge, poor primary healthcare 
Table 3 Characteristics of family screeners

\section{Family structure}

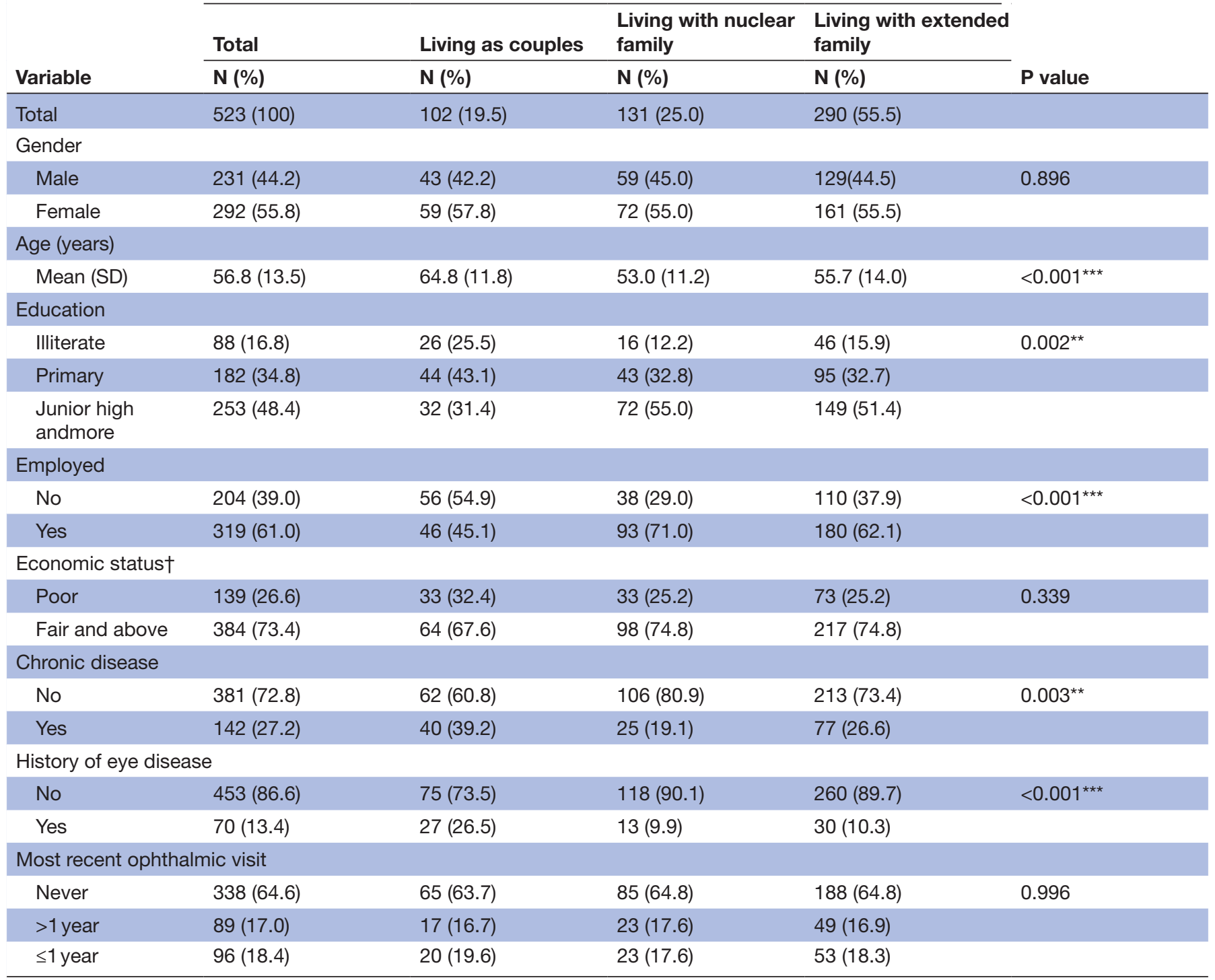

${ }^{*} \mathrm{P}$ value statistical significance: ${ }^{*} \mathrm{P}<0.05 ;{ }^{* *} \mathrm{P}<0.01 ;{ }^{* *} \mathrm{P}<0.001$.

†Economic status was measured by personal annual income (PAl) as follows: 'poor': PAI <US $\$ 725$; 'fair and above': PAI $\geq U S \$ 725$.

services. ${ }^{19-21}$ Referral barriers to family vision screening patterns remain unclear and require further research.

In this study, family structure was associated with the completeness of home-based vision testing (ie, every eligible adult was tested annually), with significantly more tests performed in nuclear and extended households than by couples. Prior research also shows that the family is an important determinant of health-seeking behaviours. ${ }^{22-24}$ A study conducted by Pradnyani et al showed that respondents living with either a nuclear or extended family have higher quality of life and better health status among the elderly, when compared with those living alone or with a spouse. ${ }^{25}$ This is consistent with insights from modernisation theorists that the health status and well-being of people are closely related to their living arrangements. ${ }^{1426}$ Although familial support is not limited to people living together, coresidence with family members has been long viewed as a contributor to happiness and well-being in China. ${ }^{27}$ Thus, it appears self-administered home vision testing programmes would be highly acceptable in China, a country dominated by nuclear and traditional extended family structures, which are based on long-standing cultural norm.

One of the keys to successful implementation of home vision screening is to find a suitable family screener. Our study indicated higher economic status and relatively young age could affect the compliance rate of being vision screeners. Other studies showed advanced economy was related to good practice of seeking eye care. ${ }^{28}$ Benzeval $e t$ $a l$ also manifested that poor people were more likely to adopt unhealthy behaviours, such as smoking and dringking, while those on higher incomes were more able to 
Table 4 Logistic regression of household screener characteristics as predictors of having performed home vision testing on at least one family member

\begin{tabular}{|c|c|c|c|c|c|c|}
\hline \multirow[b]{2}{*}{ Variable } & \multicolumn{3}{|c|}{ Univariate logistic regression } & \multicolumn{3}{|c|}{ Multivariate logistic regression } \\
\hline & OR & $95 \% \mathrm{Cl}$ & $P$ value & OR & $95 \% \mathrm{Cl}$ & $P$ value \\
\hline \multicolumn{7}{|l|}{ Gender } \\
\hline Female & 1.086 & 0.77 to 1.54 & 0.641 & & & \\
\hline \multicolumn{7}{|l|}{ Education } \\
\hline Primary school & 1.37 & 0.82 to 2.17 & 0.242 & 0.91 & 0.50 to 1.64 & 0.743 \\
\hline Junior high school and above & 2.18 & 1.36 to 3.49 & $<0.001^{\star \star \star}$ & 0.85 & 0.47 to 1.56 & 0.601 \\
\hline \multicolumn{7}{|l|}{ Employment status } \\
\hline No & Reference & & & Reference & & \\
\hline Yes & 2.13 & 1.50 to 3.02 & $<0.001^{* \star *}$ & 1.34 & 0.86 to 2.11 & 0.198 \\
\hline \multicolumn{7}{|l|}{ Presence of chronic disease } \\
\hline No & Reference & & & & & \\
\hline Yes & 0.6 & 0.41 to 0.873 & 0.08 & & & \\
\hline \multicolumn{7}{|l|}{ History of eye disease } \\
\hline No & Reference & & & & & \\
\hline Yes & 0.94 & 0.56 to 1.55 & 0.79 & & & \\
\hline \multicolumn{7}{|l|}{ Age (years) } \\
\hline$<45$ & Reference & & & Reference & & \\
\hline \multicolumn{7}{|l|}{ Family structure } \\
\hline
\end{tabular}

${ }^{*} \mathrm{P}$ value statistical significance: ${ }^{\star} \mathrm{P}<0.05 ;{ }^{* \star} \mathrm{P}<0.01 ;{ }^{* \star} \mathrm{P}<0.001$.

†Economic status was measured by personal annual income (PAI) as follows: 'poor': PAI <US $\$ 725.50$; 'fair and above': PAI $\geq U S \$ 725$.

afford healthier lifestyles because they have less pressure to work and had more free time to improve individual or family members' health. ${ }^{29}$ Therefore, we concluded economic status could be a factor influencing people's awareness and behaviour of protecting eye health. For screeners of low income, we suggest expanding their knowledge of eye diseases to promote increased participation. In addition, we tended to select relatively young adults as family screeners since they have better cognitive and comprehension skills to undertake monitoring and medical referral tasks in their home.

To the best of our knowledge, there are no published studies on home-based vision screening programmes for adults. The current study shares the main limitations of cross-sectional studies, in that results can be used to identify associations but not causation, which reduces the ability to generalise findings. Second, it will reflect an underestimated vision testing result if lay people do not put the eye chart in the right circumstance, because without enough bright sunlight, people can hardly see the optotypes which they should see on the LogMAR eye chart. Considering this is the primary vision screening, people who received the home-based vision test could get a referral to the fixed eye clinics for more comprehensive eye examination including a standardised vision test, thus eliminating the negative influences brought by their own testing bias. Finally, a formal cost-effectiveness analysis was not completed, so important questions regarding the cost-effectiveness of the YES self-administered home vision testing programme cannot be answered. Further research on cost-effectiveness outcomes of home-based vision screenings is needed. Interventions specific to those living alone or as couples may be required to increase their usage of this model.

In conclusion, the self-administered home vision test is aeffective method of detecting those with low vision and 
at risk for VI, and was highly acceptable by residents living in Wenzhou, China.

Acknowledgements The authors would like to thank all of participates for their great support which made this study possible, and all study staff from Wenzhou Medical University for their collection of data.

Contributors ZG, JQ and YL conceived and designed thissubstudy. ZG, LiL, CL, SL, YD and LC collected the data. ZG, WZ and YL have analysed the data. ZG, CL, SZ, LyL, NC and LH drafted the manuscript, and YL, LL and NC critically reviewed the manuscript. All authors have read and agree to publish the final manuscript.

Funding This study was supported by the Science and Technology Benefiting Program of Zhejiang Province, China (2014H01007), the Zhejiang Medical Science and Technology program, China (2018KY543 to Cui).

Competing interests None declared.

Patient consent for publication Obtained.

Ethics approval The cross-sectional study adhered to the guidelines in the Declaration of Helsinki. Approval was obtained from the Ethics Committee at the Wenzhou Medical University.

Provenance and peer review Not commissioned; externally peer reviewed. Data availability statement Data are available on reasonable request.

Open access This is an open access article distributed in accordance with the Creative Commons Attribution Non Commercial (CC BY-NC 4.0) license, which permits others to distribute, remix, adapt, build upon this work non-commercially, and license their derivative works on different terms, provided the original work is properly cited, appropriate credit is given, any changes made indicated, and the use is non-commercial. See: http://creativecommons.org/licenses/by-nc/4.0/.

ORCID iD

Jia Qu http://orcid.org/0000-0001-6360-2568

\section{REFERENCES}

1 Brown GC, Brown MM, Stein JD, et al. Vision-Related quality of life associated with unilateral and bilateral ocular conditions. Ophthalmology 2018;125:965-71.

2 Varma R, Wu J, Chong K, et al. Impact of severity and bilaterality of visual impairment on health-related quality of life. Ophthalmology 2006;113:1846-53.

3 Bourne RRA, Flaxman SR, Braithwaite T, et al. Magnitude, temporal trends, and projections of the global prevalence of blindness and distance and near vision impairment: a systematic review and metaanalysis. Lancet Glob Health 2017;5:e888-97.

4 World Health Organisation. Secondary blindness and vision impairment factsheet, 2018. Available: http://www.who.int/newsroom/fact-sheets/detail/blindness-and-visual-impairment [Accessed 16 Feb 2018].

5 Lee L, D'Esposito F, Garap J, et al. Rapid assessment of avoidable blindness in Papua New Guinea: a nationwide survey. $\mathrm{Br} J$ Ophthalmol 2019;103:338-42.

6 Zhang G, Tham Y-C, Gong H, et al. Blindness, low vision and cataract surgery outcome among adults in Hohhot of inner Mongolia: a rapid assessment of avoidable blindness (RAAB) study. $\mathrm{Br} \mathrm{J}$ Ophthalmol 2018;102:1653-7.

7 Gordois A, Cutler H, Pezzullo L, et al. An estimation of the worldwide economic and health burden of visual impairment. Glob Public Health 2012;7:465-81.
8 Foreman J, Xie J, Keel S, et al. Utilization of eye health-care services in Australia: the National eye health survey. Clin Exp Ophthalmol 2018;46:213-21.

9 Keel S, Xie J, Foreman J, et al. The prevalence of diabetic retinopathy in Australian adults with self-reported diabetes: the National eye health survey. Ophthalmology 2017;124:977-84.

10 Keenan J, Shahid H, Bourne RR, et al. Cambridge community Optometry glaucoma scheme. Clin Exp Ophthalmol 2015;43:221-7.

11 Pastakia SD, Ali SM, Kamano JH, et al. Screening for diabetes and hypertension in a rural low income setting in Western Kenya utilizing home-based and community-based strategies. Global Health 2013;9:21.

12 Charlton ME, Mengeling MA, Halfdanarson TR, et al. Evaluation of a home-based colorectal cancer screening intervention in a rural state. J Rural Health 2014;30:322-32.

13 Wang QM, Wang CX. Standardization of the National visual acuity chart. Chin J Optometry Ophthalmol 2013;15:577-80.

14 Turagabeci AR, Nakamura K, Kizuki M, et al. Family structure and health, how companionship acts as a buffer against ill health. Health Qual Life Outcomes 2007;5:61.

15 Lan W, Zhao F, Li Z, et al. Validation and cost-effectiveness of a home-based screening system for amblyopia. Ophthalmology 2012;119:1265-71.

16 Lim HT, Yu YS, Park S-H, et al. The Seoul metropolitan preschool vision screening programme: results from South Korea. $\mathrm{Br} J$ Ophthalmol 2004;88:929-33.

17 Freeman J, Sapyta J, Garcia A, et al. Family-based treatment of early childhood obsessive-compulsive disorder: the Pediatric ObsessiveCompulsive Disorder Treatment Study for Young Children (POTS Jr)--a randomized clinical trial. JAMA Psychiatry 2014;71:689-98.

18 Vahedian-Azimi A, Miller AC, Hajiesmaieli M, et al. Cardiac rehabilitation using the Family-Centered Empowerment model versus home-based cardiac rehabilitation in patients with myocardial infarction: a randomised controlled trial. Open Heart 2016;3:e000349.

19 Holley CD, Lee PP. Primary care provider views of the current referral-to-eye-care process: focus group results. Invest Ophthalmol Vis Sci 2010;51:1866-72.

20 Wang D, Ding X, He M, et al. Use of eye care services among diabetic patients in urban and rural China. Ophthalmology 2010;117:1755-62.

21 Boudville Al, Anjou MD, Taylor HR. Improving eye care for Indigenous Australians in primary health care settings. Aust $J$ Rural Health 2013;21:121-7.

22 Spear HJ, Kulbok PA. Adolescent health behaviors and related factors: a review. Public Health Nurs 2001;18:82-93.

23 Ohashi A, Higuchi M, Labeeb SA, et al. Family support for women's health-seeking behavior: a qualitative study in rural southern Egypt (upper Egypt). Nagoya J Med Sci 2014;76:17-25.

24 Pang EC, Jordan-Marsh M, Silverstein M, et al. Health-seeking behaviors of elderly Chinese Americans: shifts in expectations. Gerontologist 2003;43:864-74.

25 Nww P, NIp S. Family role in decision making of health seeking behavior on elderly in Tabanan Regency, Bali, Indonesia. Epidemiology 2016;06.

26 Zimmer Z. Health and Living Arrangement Transitions Among China's Oldest-Old. Res Aging 2005;27:526-55.

27 Jung J, Kim I, K-w T. Effects of living arrangements of the urban elderly on their subjective wellbeing: a comparison between Korea and China. Cogent Social Sciences2017;3.

28 Vela C, Samson E, Zunzunegui MV, et al. Eye care utilization by older adults in low, middle, and high income countries. BMC Ophthalmol 2012;12:5.

29 Benzeval M, Bond L, Campbell M, et al. Technical report 2014. How does money influence health? 2014. Available: https://researchonline. Ishtm.ac.uk/2167225/ [Accessed 16 July 2019]. 